\title{
Does raising awareness in families reduce environmental tobacco smoke exposure in wheezy children?
}

\author{
Hikmet Tekin Nacarogluㄹ, Demet Can¹, Ilker Gunay ${ }^{1}$, Canan Sule Unsal Karkıner ${ }^{1}$, Turkan Gunay², Dilek Cimrin², \\ Tugba Nalcabasmaz ${ }^{1}$
}

${ }^{1}$ Department of Pediatric Allergy, Dr Behcet Uz Children's Hospital, Izmir, Turkey ${ }^{2}$ Department of Public Health, Medical Faculty, Dokuz Eylül University, Izmir, Turkey

${ }^{3}$ Department of Biochemistry, Medical School, Dokuz Eylül University, Izmir, Turkey

\begin{abstract}
Introduction: Environmental tobacco smoke (ETS) is thought to increase the severity and number of attacks in wheezy children. Objective assessments are needed to change the behavior of families to reduce the exposure of wheezy children to ETS.

Aim: To determine whether informing families about their children's urinary cotinine levels curtailed the exposure of children to ETS.

Material and methods: A survey was used to determine the ETS exposure level, and the urinary cotinine level of each patient was tested. Children with positive urinary cotinine levels were included in the second part of the study. The families were randomly divided into two groups: an intervention group that was advised about urinary cotinine levels by telephone and a non-intervention group that was not so advised. The groups were followed-up 2 months later, and urinary cotinine levels were measured once again.

Results: The intervention group contained 65 children of average age of $24.4 \pm 8.9$ months, of whom $46(70.8 \%)$ were male. The non-intervention group contained 69 children of average age of $25.3 \pm 9.8$ months $(p>0.05)$, of whom $52(75.4 \%)$ were male. The urinary cotinine levels at the time of the second interview were lower in both groups. The number of cigarettes that fathers smoked at home decreased in the intervention group $(p=0.037)$.

Conclusions: Presenting objective evidence on ETS exposure to families draws attention to their smoking habits. Measurement of cotinine levels is cheap, practical, and noninvasive. Combined with education, creating awareness by measuring cotinine levels may be beneficial.
\end{abstract}

Key words: cotinine, children, episodic wheezing, environmental tobacco smoke.

\section{Introduction}

Environmental tobacco smoke (ETS) exposure is defined as exposure to tobacco smoke and the products thereof caused by tobacco consumption by others [1]. The World Health Organization (WHO) estimates that approximately one-half of all children in the world are exposed to ETS [2]. Because children breathe faster, they inhale toxic chemicals in tobacco smoke more intensely. Environmental tobacco smoke has both facilitative and aggravating effects on lower respiratory tract diseases, which is more obvious in early childhood[2]. Environmental tobacco smoke exposure at an early age is thought to cause inflammation of the airway mucosa and to facilitate the development of wheezing illness in the future [3-7].
Environmental tobacco smoke is one of the most important risk factors for episodic wheezing [4]. Even when warned of the dangers of ETS, families frequently do not change their smoking habits and ETS exposure continues. Objective assessments are needed to change the smoking habits of families to ensure that they cease smoking in the company of children who have episodic wheezing.

\section{Aim}

In our present study, we sought to determine whether educating such families and informing them about the urinary cotinine levels of their children would decrease ETS exposure.

Address for correspondence: Hikmet Tekin Nacaroglu MD, Department of Pediatric Allergy, Dr Behcet Uz Children's Hospital, 35220 Izmir, Turkey, phone: +90 232 4116319, e-mail: tekin212@gmail.com

Received: 28.09.2015, accepted: 22.06.2016. 


\section{Material and methods}

\section{Patients}

The study was performed in the Allergy and Immunology Department of Dr. Behcet Uz Children Hospital's (Izmir, Turkey) between December 2012 and December 2013. Children younger than 3 years with episodic wheezing were included in the study if their parents declared that they did not smoke in any environment shared by their children, although at least one person in the household was a smoker. The European Respiratory Society (ERS) classification was used to identify children with episodic wheezing [8]. Thus, preschool children who had episodic wheezing attacks triggered by viral upper respiratory tract infections and who were symptom-free between attacks were included. All participants were advised about the nature of the study and all families signed informed consent forms. The study was approved by our local Ethics Committee.

\section{Study design}

A survey instrument was first competed by the families of 237 patients eligible for the study. Training brochures on ETS exposure were prepared and they contained detailed information on ETS and the harm caused by ETS, as well as instructions about how to protect against ETS. Via the questionnaire, the number of parents smoking at home, the number of cigarettes smoked daily both at home and outside, and the presence or absence of smoking bans at home were explored. Urinary cotinine levels were measured in children. Of these, 193 participants who had a positive urinary cotinine level were randomly divided into two groups: an intervention group that was informed about their urinary cotinine levels and a non-intervention group that was not informed. The intervention group was given education about the harm by ETS exposure and ways to avoid it, and the other group was not.

The urinary cotinine levels of the two groups were measured again 2 months later, and the survey was repeated (Figure 1). Finally, the groups were compared in terms of alterations in cotinine levels and changes in family attitudes to smoking indoors.

\section{Urinary cotinine level}

Urinary cotinine levels were measured (in $\mathrm{ng} / \mathrm{ml}$ ) using an IMMULITE 2000 (Siemens, USA) chemiluminescence assay employing an IMMULITE 2000 nicotine metabolite kit. The manufacturer indicated that $10 \mathrm{ng} /$ $\mathrm{ml}$ was the limit for ETS exposure. A value below this threshold indicated "no ETS exposure" and a value of 10 ng/ml or greater indicated "ETS exposure."

\section{Statistical analysis}

The Statistical Package for the Social Sciences version 19.0 was used in statistical analyses. The $\chi^{2}$ test was used to compare grouped data. The paired t-test was used to compare group-specific measurements and the independent Student's t-test to compare measurements among independent groups. Pearson's correlation analysis was used to explore correlations between the measurements. $P$-values $<0.05$ were considered statistically significant.

\section{Results}

Cotinine was present in the urine of 193 (81.4\%) of the 237 children who participated in the study. The average cotinine level was $46.1 \pm 57.9 \mathrm{ng} / \mathrm{ml}$ in the intervention group and $48.1 \pm 54.1 \mathrm{ng} / \mathrm{ml}$ in the non-intervention group (Figure 2). We found no significant difference in early cotinine levels between the two groups $(p=0.836)$. Fifty-nine (30.5\%) subjects did not attend their follow-up visits, including 32 (16.5\%) from the intervention group and 27 (14\%) from the non-intervention group. These subjects were excluded from the study. Application of the "intention to treat" test showed that the data of subjects who were excluded did not change the results.

The intervention group included 65 children: 46 (70.8\%) males and 19 (29.2\%) females. The non-intervention group consisted of 69 children: 52 (75.4\%) males and 17 (24.6\%) females. The average age of children in the intervention group was $24.4 \pm 8.9$ months, and the aver-

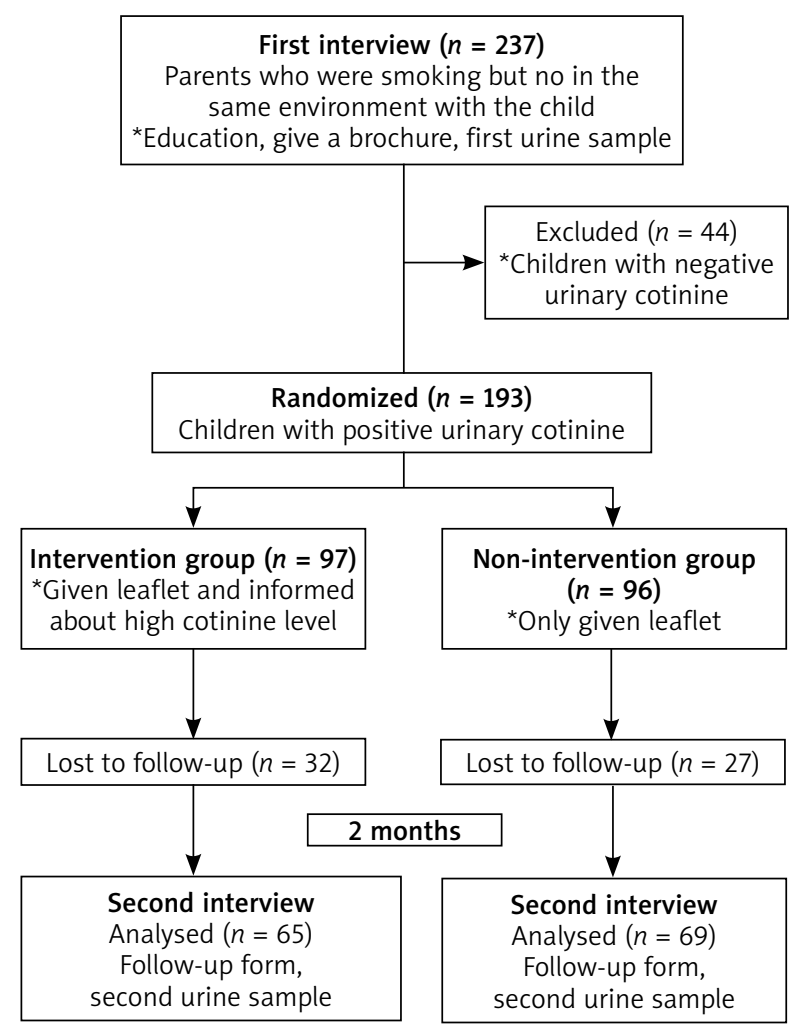

Figure 1. Study flow diagram 


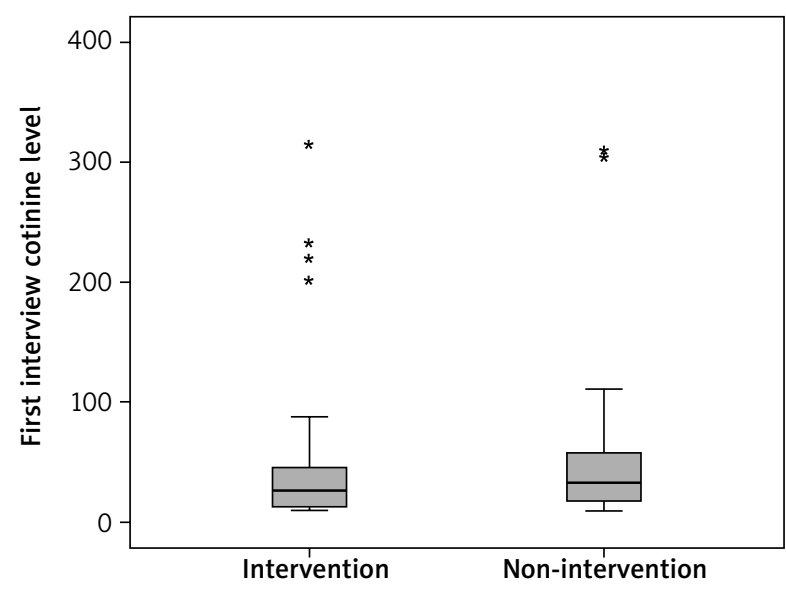

Figure 2. First interview cotinine level

age age in the non-intervention group $25.3 \pm 9.8$ months. There was no significant difference between the intervention and non-intervention groups with respect to the sex of the children or the age or educational levels of the parents $(p=0.549, p=0.779, p=0.292$ and $p=0.733$, respectively) (Table 1 ). According to data obtained in the first survey, $87.6 \%$ of fathers and $52.3 \%$ of mothers in the intervention group, and $76.8 \%$ of fathers and $52.1 \%$ of mothers in the non-intervention group, were smokers. Mothers who smoked only in areas from which children were excluded constituted $32.3 \%$ of the intervention group, $37.9 \%$ of the non-intervention group, and $35.1 \%$ in total. Fathers who smoked only in areas where children were not present constituted $81.5 \%$ of the intervention group, $73.9 \%$ of the non-intervention group, and $77.6 \%$ in total; exposure to fathers' smoking was thus twice that of exposure to mothers' smoking.

When the correlations between the number of cigarettes to which children were exposed and urinary cotinine levels were examined, it was clear that the more cigarettes smoked near children, the higher the level of cotinine in their urine $(p<0.05)$. Although the correlation between the urinary cotinine level and the number of cigarettes smoked daily by the father at home was low $(r=0.193)$, it was nonetheless statistically significant $(p=0.04)$. The correlation between the urinary cotinine level and the number of cigarettes smoked daily by the mother at home was high $(r=0.559)$, and the number of cigarettes the mother smoked daily at home was strongly associated with the cotinine level in children $(p<0.001)$. We found a moderate correlation between the urinary cotinine level and the number of cigarettes smoked daily at home $(r=0.364)$. As the number of cigarettes smoked daily at home increased, the cotinine level also rose $(p<0.001)$ (Table 2$)$.

At the time of the second interview, the cotinine levels were $41.2 \pm 57.8 \mathrm{ng} / \mathrm{ml}$ in the intervention group and $40.8 \pm 43.3 \mathrm{ng} / \mathrm{ml}$ in the non-intervention group (Figure 3). Although the cotinine level of children in the intervention group was thus reduced at the time of the second interview, no significant difference was evident between the two surveys ( $p=0.355)$. In the intervention group, significant decreases in the number of cigarettes

Table 1. The distribution of groups according to the results of the first survey

\begin{tabular}{|c|c|c|c|c|}
\hline \multicolumn{2}{|l|}{ Parameter } & \multirow{2}{*}{$\begin{array}{c}\text { Intervention group } \\
46(70.8)\end{array}$} & \multirow{2}{*}{$\frac{\text { Non-intervention group }}{52(75.4)}$} & \multirow{2}{*}{$\begin{array}{c}P \text {-value } \\
0.549\end{array}$} \\
\hline Gender, $n(\%)$ & Boy & & & \\
\hline & Girl & $19(29.2)$ & $17(24.6)$ & \\
\hline \multicolumn{2}{|l|}{ Age at admission [months] } & $24.4 \pm 8.9$ & $25.3 \pm 9.8$ & 0.779 \\
\hline \multirow[t]{2}{*}{ Educational status of mothers', $n(\%)$} & Primary school & $37(56.9)$ & $33(47.8)$ & 0.292 \\
\hline & High school & $28(43.1)$ & $36(52.2)$ & \\
\hline \multirow[t]{2}{*}{ Educational status of fathers', $n(\%)$} & Primary school & $33(50.8 \%)$ & $33(47.8)$ & 0.733 \\
\hline & High school & $32(4.2 \%)$ & $36(52.2)$ & \\
\hline \multicolumn{2}{|l|}{ Number of smoking fathers, $n(\%)$} & $57(87.6)$ & $53(76.8)$ & 0.362 \\
\hline \multicolumn{2}{|l|}{ Number of smoking mothers, $n(\%)$} & $34(52.3)$ & $36(52.1)$ & 0.510 \\
\hline \multicolumn{2}{|l|}{ Number of fathers smoking at home, $n(\%)$} & $53(81.5)$ & $51(73.9)$ & 0.290 \\
\hline \multicolumn{2}{|c|}{ Number of mothers smoking at home, $n(\%)$} & $21(32.3)$ & $26(37.6)$ & 0.515 \\
\hline \multicolumn{2}{|c|}{ Total number of cigarettes smoked at home daily } & $12.6 \pm 11.9^{*}$ & $11.5 \pm 11.9^{*}$ & 0.619 \\
\hline \multicolumn{2}{|c|}{ Number of cigarettes smoked by mother daily } & $11.4 \pm 7.7^{*}$ & $9.02 \pm 6.1^{*}$ & 0.336 \\
\hline \multicolumn{2}{|c|}{ Number of cigarettes smoked by father daily } & $16.8 \pm 10.3^{*}$ & $16.9 \pm 9.2^{*}$ & 0.408 \\
\hline \multicolumn{2}{|c|}{ Number of cigarettes smoked by mother at home daily } & $7.1 \pm 3.9^{\star}$ & $5.9 \pm 4.1^{\star}$ & 0.268 \\
\hline \multicolumn{2}{|c|}{ Number of cigarettes smoked by father at home daily } & $7.7 \pm 7.1^{\star}$ & $6.3 \pm 4.7^{\star}$ & 0.206 \\
\hline
\end{tabular}

*Data are shown as mean \pm standard deviation for normally distributed variables. 
Table 2. Correlation between the number of cigarettes and the urinary cotinine level of children involved in the study

\begin{tabular}{lcc}
\hline Variable & $r$ & $P$-value \\
\hline $\begin{array}{l}\text { Number of cigarettes smoked by father } \\
\text { at home daily }\end{array}$ & 0.193 & 0.040 \\
\hline $\begin{array}{l}\text { Number of cigarettes smoked by mother } \\
\text { at home daily }\end{array}$ & 0.559 & $<0.001$ \\
\hline $\begin{array}{l}\text { Total number of cigarettes smoked by } \\
\text { parents at home daily }\end{array}$ & 0.364 & $<0.001$ \\
\hline $\begin{array}{l}\text { Pearson correlation test. } \\
\text { Par }\end{array}$ & & \\
\hline
\end{tabular}

that fathers smoked both daily and at home were evident ( $p=0.001$ and $p=0.001$, respectively). Although the number of cigarettes smoked daily by mothers both at home and outside decreased, the decreases were insignificant ( $p=0.272$ and $p=0.376$, respectively). Thus, although the cotinine level of children in the control group was lower at the time of the second interview than at the first, this change was not significant ( $p=0.101)$. We also found no significant changes in the numbers of cigarettes that fathers and mothers smoked either outside or at home (both $p$-values > 0.05) (Table 3).

Twenty (14.9\%) cases in whom cotinine levels became negative for ETS exposure and 114 (85.1\%) in whom cotinine levels remained positive were compared in terms of parental behaviors that would lower ETS exposure. The only behavioral factor significantly related to a shift from positive to negative cotinine levels was a suggestion by one spouse to the other that he/she should quit smoking $(p=0.021)$. Apart from that, there was no significant difference between groups in terms of behavioral changes $(p>0.05)$ (Table 4). We found no correlation between

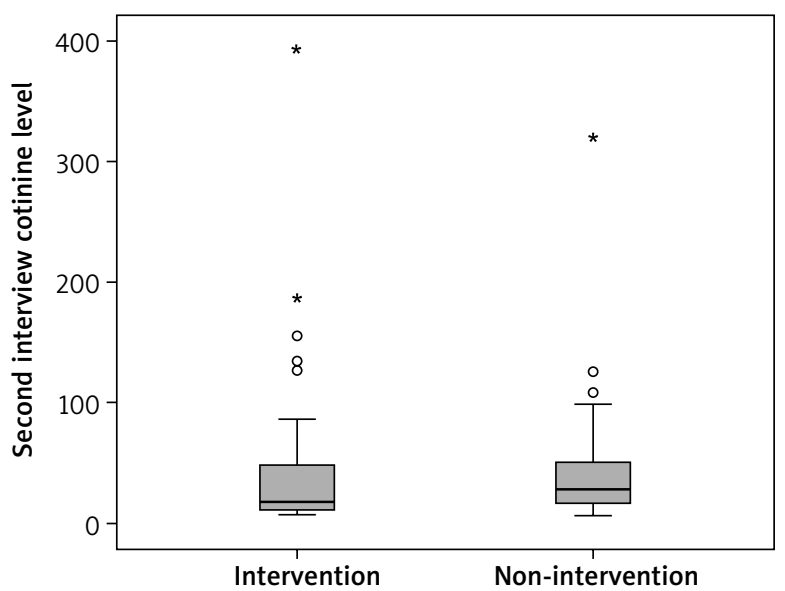

Figure 3. Second interview cotinine level

the educational levels of mothers $(r=0.023, p=0.791)$ or fathers ( $r=-0.036, p=0.683)$ of children related to continuous ETS exposure among the children.

\section{Discussion}

Although exposure of children to ETS is highest in developing countries, such exposure is relatively high, 29-69\%, worldwide [9]. Urinary cotinine levels are used to evaluate ETS exposure levels in epidemiological research because the test is easy to use, accurate, and highly sensitive, and it can be performed more often than evaluation of serum cotinine levels, which require blood sampling [10-13]. To provide an objective measure of ETS exposure, we evaluated urinary cotinine levels. In line with previous research, we found no correlation

Table 3. Influence levels of environmental tobacco exposure in the first and second interviews of intervention and nonintervention groups

\begin{tabular}{|c|c|c|c|c|}
\hline Variable & Group & First interview & Second interview & $P$-value \\
\hline \multirow[t]{2}{*}{ Cotinine level } & $\begin{array}{l}\text { Intervention } \\
\text { (median, min-max) }\end{array}$ & $\begin{array}{c}46.14 \pm 57.99 \\
(26.3,10.1-314)\end{array}$ & $\begin{array}{c}41.2 \pm 57.8 \\
(18.4,7-394)\end{array}$ & 0.355 \\
\hline & $\begin{array}{l}\text { Non-intervention } \\
\text { (median, min-max) }\end{array}$ & $\begin{array}{c}48.16 \pm 54.17 \\
(33,10.1-310)\end{array}$ & $\begin{array}{c}40.8 \pm 43.3 \\
(28.8,7-321)\end{array}$ & 0.101 \\
\hline \multirow{2}{*}{$\begin{array}{l}\text { Number of cigarettes smoked by mother } \\
\text { daily }\end{array}$} & Intervention & $11.4 \pm 7.73$ & $11.1 \pm 8.59$ & 0.272 \\
\hline & Non-intervention & $9.02 \pm 6.10$ & $9.65 \pm 8.30$ & 0.672 \\
\hline \multirow{2}{*}{$\begin{array}{l}\text { Number of cigarettes smoked by father } \\
\text { daily }\end{array}$} & Intervention & $16.8 \pm 10.3$ & $14.5 \pm 9.01$ & 0.001 \\
\hline & Non-intervention & $16.9 \pm 9.23$ & $15.3 \pm 8.62$ & 0.190 \\
\hline \multirow{2}{*}{$\begin{array}{l}\text { Number of cigarettes smoked by mother } \\
\text { at home }\end{array}$} & Intervention & $7.12 \pm 3.94$ & $6.19 \pm 4.66$ & 0.376 \\
\hline & Non-intervention & $5.89 \pm 4.05$ & $5.69 \pm 4.38$ & 0.927 \\
\hline \multirow{2}{*}{$\begin{array}{l}\text { Number of cigarettes smoked by father } \\
\text { at home }\end{array}$} & Intervention & $7.69 \pm 7.08$ & $3.96 \pm 3.62$ & 0.001 \\
\hline & Non-intervention & $6.27 \pm 4.66$ & $5.09 \pm 5.56$ & 0.615 \\
\hline
\end{tabular}

Data are shown as mean \pm standard deviation for normally distributed variables. 
Table 4. Distribution of the behaviour change executed by families of cases whose ETS exposure disappeared or continued

\begin{tabular}{lccc}
\hline Variable & $\begin{array}{c}\text { Cases whose ETS } \\
\text { exposure continued } \\
n(\%)\end{array}$ & $\begin{array}{c}\text { Cases whose ETS } \\
\text { exposure disappeared } \\
n(\%)\end{array}$ & $P$-value \\
\hline I did nothing & $54(47.4)$ & $9(45)$ & 0.845 \\
\hline I took the child away from smoking area & $14(12.2)$ & $4(20)$ & 0.350 \\
\hline I opened the window & $3(2.6)$ & $0(0)$ & 0.463 \\
\hline I put up a "no smoking" notice & $3(2.6)$ & $1(5)$ & 0.566 \\
\hline I told my spouse to smoke less & $14(12.3)$ & $3(15)$ & 0.736 \\
\hline I told my spouse not to smoke at home & $23(20.2)$ & $6(30)$ & 0.325 \\
\hline I told my spouse not to smoke near the child & $15(13.2)$ & $1(5)$ & 0.299 \\
\hline I told my spouse to put off a cigarette before coming near the child & $3(2.6)$ & $1(5)$ & 0.566 \\
\hline I recommended my spouse to quit smoking & $6(5.3)$ & $4(20)$ & 0.021 \\
\hline
\end{tabular}

between child urinary cotinine levels and parentally reported ETS exposure levels, suggesting that parents, consciously or unconsciously, do not acknowledge ETS exposure, or report incomplete information [14-17]. We also found high urinary cotinine levels in the children of parents who claimed that they never smoked when their children were nearby. In the present study, the ETS exposure level was $81.4 \%$. Such a high level may be attributable to a lack of parental awareness rather than conscious untruth, with the parents not realizing that smoking at home, irrespective of whether the children are present, exposes the children to ETS.

Although parents may be aware of the damage caused by ETS to child health, it is very difficult to change smoking habits because smoking is addictive [18]. Interventions aimed at changing attitudes and behaviors in terms of smoking at home are important to reduce the incidence of respiratory tract diseases caused by ETS and to prevent ETS exposure in children. Many recent studies have investigated the effectiveness of various interventions. Some studies have suggested that informing parents about the urinary cotinine levels of their children is more influential than simple training. Wilson et al. [19] consulted mothers with asthmatic children on the levels of ETS exposure and then informed the mothers about their children's urinary cotinine levels. In that study, information on cotinine levels was more successful in reducing admissions to hospital than a training-based intervention. Emmons et al. [20] determined that a limited intervention targeting parents who smoked and using only educational materials was not effective in decreasing the ETS exposure of children aged 3 years or younger. Wakefield et al. [21] studied households in South Australia where at least one parent smoked. The intervention involved informing parents by mail and telephone (twice) of the urinary cotinine levels of the children. They found that this approach was more successful than an intervention featuring only education, and it increased the fre- quency of banning smoking at home. Ekerbicer et al. [22] also reported that imposition of smoking bans at home increased after parents were informed by mail about the urinary cotinine levels of their children. In a study of mothers of 108 children under 4 years of age, Hovell et al. [2] found that the number of weekly home exposures to cigarette smoking in the intervention group was significantly lower than that in the control group. Yücel et al. [23] showed in a study of 80 mothers that ETS exposure of their children decreased after either comprehensive or limited training interventions. Compliance with smoking bans at home was higher among mothers in the intervention groups. Wilson et al. [24] showed in a study of 519 asthmatic children that training the parents and informing them about cotinine levels were effective in reducing the frequency of child asthma attacks.

In studies comparing different approaches, it is very important that the groups exhibit similar distributions of features that may affect the results. The present study included patients who were followed up for episodic wheezing and whose parents stated that they did not smoke near their children. The children with positive urinary cotinine levels were randomly divided into two groups. We found no difference between the groups in terms of basic variables such as smoking status prior to intervention, sociodemographic features such as the gender of the children, or the average age or educational backgrounds of the parents. Thus, the two groups were statistically comparable. There was a significant decrease in the number of total cigarettes that the fathers smoked after learning about urinary cotinine levels, and also in the number of cigarettes smoked at home. This outcome is particularly crucial in terms of changing the smoking habits of fathers at home in Turkey, where the frequency of smoking is higher among men than among women.

The ETS exposure of $14.9 \%$ of the children involved in the study was eliminated during the study, as indicated by negative ETS test results. When we analyzed the behav- 
iors of families in which ETS exposure was reduced, the frequency of suggesting that a spouse should quit smoking was significantly higher among the families of children whose ETS exposure was eliminated. This shows that education alone can be effective in decreasing ETS exposure. Although the urinary cotinine level became negative in a somewhat greater number of children in the intervention group, no significant difference was evident between the two groups in this regard. This highlights the need to reinforce our approach with recurrent follow-up interviews to enhance parental knowledge and awareness.

In the present study, we found a moderate correlation between the urinary cotinine level and the number of cigarettes smoked at home. As the number of cigarettes smoked at home increased, the urinary cotinine level also rose. Irvine et al. [10] found positive correlations of the number of cigarettes smoked at home and the number of smokers at home with the urinary cotinine levels of children. Keskinoglu et al. [9] reported that when the number of smokers at home and the number of cigarettes smoked at home increased, urinary cotinine levels in children rose significantly as children aged. Mannino et al. [25] found positive correlations of the number of cigarettes smoked and the number of smokers at home with increased cotinine levels in children. When the number of cigarettes smoked by mothers was compared with that smoked by fathers, the correlation between the number of cigarettes smoked by mothers and the urinary cotinine level of the children was higher. This finding shows that children in Turkey are at a greater risk of ETS exposure from mothers than from fathers who smoke, as the mothers are mostly homemakers and spend more time with their children than fathers.

The limitations of this study are that we did not investigate the effect of ETS exposure on airway inflammation or the frequency and severity of attacks in children subjected to ETS exposure and exhibiting episodic wheezing. Clinical follow-up of wheezing cases associated with ETS exposure will enable the effectiveness of various approaches to be evaluated in further studies.

\section{Conclusions}

To help control wheezing attacks, which are important causes of morbidity in childhood, ETS exposure must be prevented at home where children spend most of their time. As shown in the present study, ETS exposure cannot be reliably estimated based on the reports of parents. This study indicates that training families on the effects of ETS exposure is crucial; however, informing parents of the urinary cotinine levels of their children has not yet been very effective. More influential strategies are required to reveal the effects of ETS exposure to families more objectively. We consider that the cost of such strategies is of little importance when it is recognized that protection of even one wheezy child at risk from ETS exposure would save a great deal of money. In high-risk cases, cotinine measurements should indeed continue to be considered.

\section{Conflict of interest}

The authors declare no conflict of interest.

\section{References}

1. World Health Organization. International Consultation on Environmental Tobacco Smoke (ETS) and Child Health. WHO 1999; 11-14 January, Geneva, Switzerland, 1-29.

2. Hovell MF, Zakarian JM, Wahlgren DR, et al. Reported measures of environmental tobacco smoke exposure: trials and tribulations. Tob Control 2000; 9: 22-8.

3. Cook DG, Strachan DP, Carey IM. Health effects of passive smoking. 9. Parental smoking and spirometric indices in children. Thorax 1998; 53: 884-93.

4. Shiva F, Nasiri M, Sadeghi B, Padyap M. Effects of passive smoking on common respiratory symptoms in young children. Acta Paediatr 2003; 92: 1394-7.

5. Giovanni P. Contribution of neuroimmune mechanisms to airway inflammation and remodeling during and after respiratory syncytial virus infection. Pediatr Infec Dis J 2003; 22: 66-75.

6. Martinez FD. New insights into the natural history of asthma: primary prevention on the horizon. J Allergy Clin Immunol 2011; 128: 939-45.

7. Di Franza JR, Aligne CA, Weitzman M. Prenatal and postnatal environmental tobacco smoke exposure and childrens health. Pediatrics 2004; 113: 1007-15.

8. Brand PL, Baraldi E, Bisgaard H, et al. ERS task force. Definition, assessment and treatment of wheezing disorders in preschool children: an evidence-based approach. Eur Respir J 2008; 32: 1096-110.

9. Keskinoglu P, Cimrin D, Aksakoglu G. Relationships between cotinine, lower respiratory tract infection, and eosinophil cationic protein in children. Eur J Pediatr 2007; 166: 455-9.

10. Irvine L, Crombie IK, Clark RA, et al. What determines levels of passive smoking in children with asthma? Thorax 1997; 52: 766-9.

11. Cobanoglu N, Kiper N, Dilber E, et al. Environmental tobacco smoke exposure and respiratory morbidity in children. Inhal Toxicol 2007; 19: 779-85.

12. Willers S, Axmon A, Feyerabend C, et al. Assessment of enviromental tobbacco smoke exposure in children with asthmatic symptoms by questionnaire and cotinine concentrations in plasma, saliva, and urine. J Clin Epidemiol 2000; 53: 715-21.

13. Priest N, Roseby R, Waters E, et al. Family and career smoking control programmes for reducing children's exposure to environmental tobacco smoke. Cochrane Database Syst Rev 2008; 4: CD001746.

14. Cornelius MD, Goldschmidt L, Dempsey DA. Environmental tobacco smoke exposure in low-income 6-year-olds: parent report and urine cotinine measures. Nicotine Tob Res 2003; 5: 333-9.

15. Derauf C, Katz AR, Easa D. Agreement between maternal self-reported ethanol intake and tobacco use during pregnancy and meconium assays for fatty acid ethyl esters and cotinine. Am J Epidemiol 2003; 158: 705-9.

16. Seccareccia F, Zuccaro P, Pacifici R, et al. Research Group of the MATISS. Serum cotinine as a marker of environmental tobacco smoke exposure in epidemiological studies: the 
experience of the MATISS project. Eur J Epidemiol 2003; 18: 487-92.

17. Karadag B, Karakoc F, Ceran O, et al. Does passive smoke exposure trigger acute asthma attack in children? Allergol Immunopathol (Madr) 2003; 31: 318-23.

18. Mcintosh NA, Clark NM, Howatt WF. Reducing tobacco smoke in the environment of the child with asthma: a cotinine-assisted, minimal-contact intervention. J Asthma 1994; 31: 453-62.

19. Wilson SR, Yamada EG, Sudhakar R, et al. A controlled trial of an environmental tobacco smoke reduction intervention in low-income children with asthma. Chest 2001; 120: 1709-22.

20. Emmons KM, Hammond SK, Fava JL, et al. A randomized trial to reduce passive smoke exposure in low-income households with young children. Pediatrics 2001; 108: 18-24.

21. Wakefield M, Banham D, McCaul K, et al. Effect of feedback regarding urinary cotinine and brief tailored advice on home smoking restrictions among low-income parents of children with asthma: a controlled trial. Prevent Med 2002; 34: 58-65.

22. Ekerbicer HC, Celik M, Guler E, et al. Evaluating environmental tobacco smoke exposure in a group of Turkish primary school students and developing intervention methods for prevention. BMC Public Health 2007; 7: 1-6.

23. Yücel U, Ocek ZA, Ciçeklioğlu M. Evaluation of an intensive intervention programme to protect children aged 1-5 years from environmental tobacco smoke exposure at home in Turkey. Health Educ Res 2014; 29: 442-55.

24. Wilson SR, Farber HJ, Knowles SB, Lavori PW. A randomized trial of parental behavioral counseling and cotinine feedback for lowering environmental tobacco smoke exposure in children with asthma: results of the LET'S Manage Asthma trial. Chest 2011; 139: 581-90.

25. Mannino DM, Caraballo R, Benowitz N, Repace J. Predictors of cotinine levels in US children: data from The Third National Health and Nutrition Examination Survey. Chest 2001; 120: 718-24. 